07

\title{
Применение покрытий AIN для защиты поверхности гетероструктур системы AIGaAs/GaAs от взаимодействия с атмосферным кислородом
}

\author{
(C) Е.В. Фомин ${ }^{1}$, А.Д. Бондарев ${ }^{2}$, И.П. Сошников ${ }^{2,3}$, N.B. Bercu ${ }^{4}$, L. Giraudet $^{4}$, M. Molinari $^{4}$, T. Maurer $^{5}$, \\ Н.A. Пихтин ${ }^{1,2}$
}

${ }^{1}$ Санкт-Петербургский государственный электротехнический университет „ЛЭТИ“, Санкт-Петербург, Россия

${ }^{2}$ Физико-технический институт им. А.Ф. Иоффре РАН,

Санкт-Петербург, Россия

${ }^{3}$ Санкт-Петербургский национальный исследовательский Академический университет им. Ж.И. Алфёрова РАН, Санкт-Петербург, Россия

${ }^{4}$ Laboratoire de Recherche en Nanosciences, Université de Reims Champagne-Ardenne,

Reims, France

${ }^{5}$ Laboratoire de Nanotechnologie et d'Instrumentation Optique, ICD CNRS UMR 6281, Université de Technologie de Troyes, Troyes, France

E-mail: evgeny.fomin@bk.ru

Поступило в Редакцию 28 октября 2019 г.

В окончательной редакции 16 декабря 2019 г.

Принято к публикации 16 декабря 2019 г.

\begin{abstract}
Представлены результаты синтеза методом реактивного ионно-плазменного распыления тонких пленок нитрида алюминия и исследования их свойств с целью применения в качестве защитных покрытий торцевых резонаторов мощных полупроводниковых лазерных гетероструктур $\mathrm{Al}_{x} \mathrm{Ga}_{1-x} \mathrm{As} / \mathrm{GaAs}$. Исследования методом энергодисперсионной рентгеновской спектроскопии и результаты эллипсометрии показали, что при остаточном давлении в камере порядка $\sim 10^{-5}$ Torr в пленках образуется слой оксинитрида алюминия. При этом гетерограница пленка-подложка может претерпеть окисление. Однако пленки AlN толщиной порядка $100 \mathrm{~nm}$, выращенные в среде чистого азота при остаточном давлении $\sim 10^{-7}$ Torr, по-видимому, не содержат в составе кислород и могут надежно препятствовать его проникновению в область гетерограницы. Потенциально они могут служить эффективной защитой для гетероструктур, чувствительных к окислению.
\end{abstract}

Ключевые слова: полупроводниковые лазеры, тонкие пленки, пассивация, нитрид алюминия, деградация лазеров.

DOI: 10.21883/PJTF.2020.06.49158.18088

Полупроводниковые лазеры находят все более широкое применение в современном мире, и с развитием технологий растут требования к устройствам. Одно из основных требований к таким приборам - надежность и долговечность. Особое значение указанные требования имеют для мощных полупроводниковых лазеров, которые во время работы подвергаются экстремально высоким нагрузкам ввиду большой плотности мощности генерируемого излучения. Для таких лазеров особенно остро стоит вопрос катастрофической оптической деградации зеркал (COMD), при возникновении которой в короткие сроки падает выходная мощность лазера и устройство выходит из строя [1-3]. Одним из методов борьбы с деградацией зеркал является пассивация выходных граней гетероструктуры, например, с помощью химической обработки или нанесения специальных покрытий, предотвращающих взаимодействие выходного резонатора с атмосферой [4-7]. В то же время для эффективной работы лазеров обычно требуется нанесение оптических покрытий - просветляющих или отражающих, которые должны обеспечить эффективную генерацию и вывод излучения [8]. Существует вариант нанесения нескольких слоев покрытий из разных материалов, один из которых играет пассивирующую роль, а другой обеспечивает необходимый коэффициент отражения $[1,6]$. Также возможно раскалывание гетероструктуры в вакууме с последующим нанесением просветляющего покрытия без извлечения гетероструктуры на воздух [5,7]. Указанные способы могут быть эффективны, но они значительно усложняют процесс. В качестве материалов просветляющих и отражающих покрытий нашли широкое применение $\mathrm{Al}_{2} \mathrm{O}_{3}$ и $\mathrm{Si} / \mathrm{SiO}_{2}$. Технологии их получения просты и хорошо отработаны, однако эти материалы неэффективны для пассивации гетероструктур системы AlGaAs, поскольку содержат в составе кислород. Известно, что алюминий в области волновода лазера системы AlGaAs подвержен окислению [9]. Окисление поверхности может привести к возникновению дефектов в области волновода $\mathrm{AlGaAs-лазера,} \mathrm{что} \mathrm{ве-}$ дет к паразитному поглощению выводимого излучения, возникновению безызлучательной рекомбинации и локальному нагреву волноводной области. В дальнейшем 

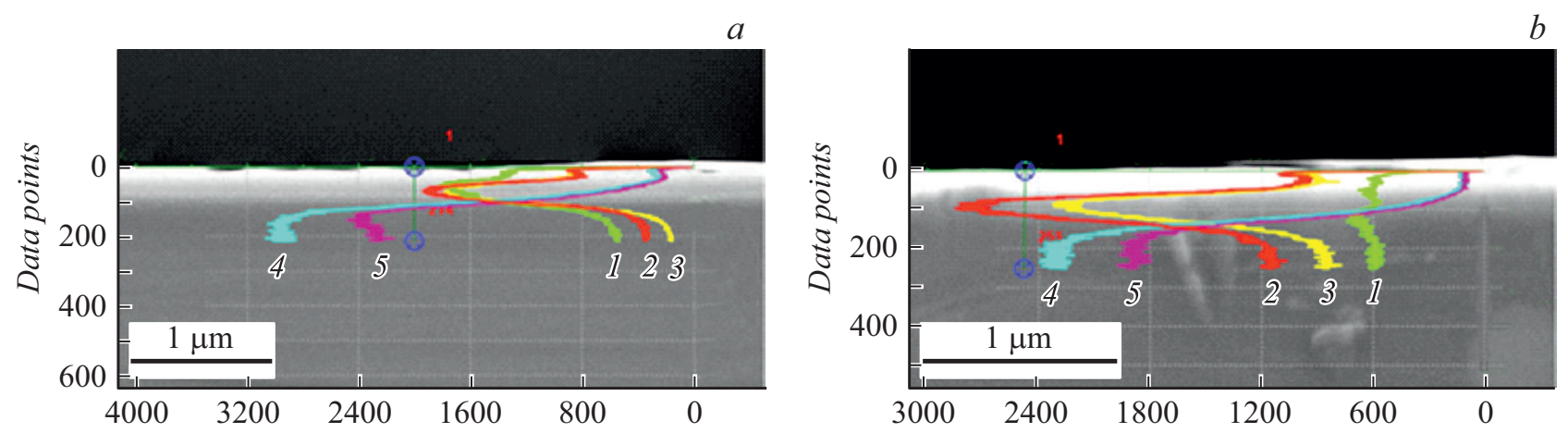

Рис. 1. РЭМ-изображения свежих сколов образцов. $a-$ образец № $1, b-$ образец № 2. Показаны линии сканирования, а также относительные концентрации элементов в пленках: $1-\mathrm{O}, 2-\mathrm{Al}, 3-\mathrm{N}, 4-\mathrm{Ga}, 5-\mathrm{As}$.

из-за повышения температуры дефекты разрастаются, происходит разрушение зеркала и деградация лазера [3]. Таким образом, задача разработки покрытия, способного выполнять одновременно функции просветляющего и защитного, для зеркал мощных полупроводниковых лазеров системы AlGaAs является актуальной и важной.

В настоящей работе проводятся исследования процесса синтеза пленок AlN методом реактивного ионно-плазменного распыления, их свойств и оценивается возможность их применения в качестве защитных покрытий для резонаторов мощных полупроводниковых лазеров $\mathrm{AlGaAs} / \mathrm{GaAs}$.

Пленки AlN были получены методом реактивного ионно-плазменного распыления мишени из чистого $\mathrm{Al}$ в среде осч $\mathrm{N}_{2}$ без добавления иных рабочих газов в вакуумной установке триодного типа. В качестве подложек использовались ері-ready пластины $n$-GaAs с ориентацией (100). При подготовке к процессу осаждения производилась откачка камеры, после чего выполнялась чистка поверхности образцов с помощью травления в плазме $\mathrm{Ar}^{+}$при отрицательном смещении на образце $-20 \mathrm{~V}$. Алюминиевая мишень также подвергалась травлению в плазме аргона с целью очистки поверхности перед распылением от естественной оксидной пленки. Давление рабочих газов в процессе предварительной очистки и в процессе осаждения пленки поддерживалось на уровне $(2-4) \cdot 10^{-3}$ Torr. Чистота рабочих газов и алюминиевой мишени не хуже $99.999 \%$.

Для работы была подготовлена серия образцов, полученных при значении остаточного давления от $\sim 5 \cdot 10^{-5}$ до $\sim 7 \cdot 10^{-7}$ Torr. После напыления проводилась оценка толщины $d$ и показателя преломления $n$ пленок с помощью эллипсометра ЛЭФ-3М-1 на длине волны $l=633 \mathrm{~nm}$. Толщины образцов дополнительно уточнялись с помощью растровой электронной микроскопии на оборудовании C. Zeiss Supra 25. Далее образцы пленок выдерживались при „комнатных“ атмосферных условиях не менее полугода, после чего были проведены повторные исследования эллипсометрии, а также качественная оценка химического состава методом энергодисперсионной рентгеновской спектроскопии (ЭДС). Исследования
Характеристики пленок AlN

\begin{tabular}{c|c|c|c|c}
\hline $\begin{array}{c}\text { Номер } \\
\text { образца }\end{array}$ & $\begin{array}{c}\text { Остаточное } \\
\text { давление } \\
P_{0}, \text { Torr }\end{array}$ & $\begin{array}{c}\text { Толщина } \\
\text { пленки } \\
d, \mathrm{~nm}\end{array}$ & $\begin{array}{c}\text { Показатель } \\
\text { преломления } \\
n\end{array}$ & $\begin{array}{c}\text { Скорость } \\
\text { роста } \\
v, \AA / \mathrm{min}\end{array}$ \\
\hline 1 & $5 \cdot 10^{-5}$ & 124.7 & 1.735 & 122 \\
2 & $7 \cdot 10^{-7}$ & 123.4 & 2.115 & 83
\end{tabular}

методом ЭДС проводились при ускоряющем напряжении $5 \mathrm{keV}$ с помощью детектора EDAX Octane Elite Super, установленного на растровом электронном микроскопе (РЭМ) JEOL 7900F. Сканирование проводилось поперек свежего скола торца образцов, как показано на рис. $1, a, b$. Это позволяет оценить профиль распределения химических элементов в пленке и подложке и в некоторой степени получить представление об интерфейсе пленка-подложка. С учетом ускоряющего напряжения глубина сканирования оценивается в $500-550 \mathrm{~nm}$ от поверхности пленки.

Характеристики наиболее показательных образцов приведены в таблице. Исследование методом ЭДС показывает, что интерфейс пленка-подложка и сама пленка AlN в образце № 1 (рис. 1,a) имеют явный градиент интенсивности вторичной электронной эмиссии. Это может свидетельствовать о том, что изначально на подложке формируется аморфный подслой оксинитрида алюминия, но с увеличением толщины пленка постепенно кристаллизуется. Такое поведение было ранее продемонстрировано в работах [10-12]. Это объясняет низкий показатель преломления образца № 1 относительно теоретического значения ( 1.74 против $2.1-2.4)$. Для таких частично аморфных пленок также характерны более высокие скорости роста (вплоть до полуторакратного увеличения относительно скорости роста нанокристаллических). В случае понижения остаточного давления до $7 \cdot 10^{-7}$ Torr в образце № 2 (рис. $1, b$ ) на РЭМ-изображении наблюдается значительный контраст между подложкой и пленкой, при этом градиент интенсивности вторичной электронной эмиссии в самой пленке выражен значительно слабее, что указывает на 

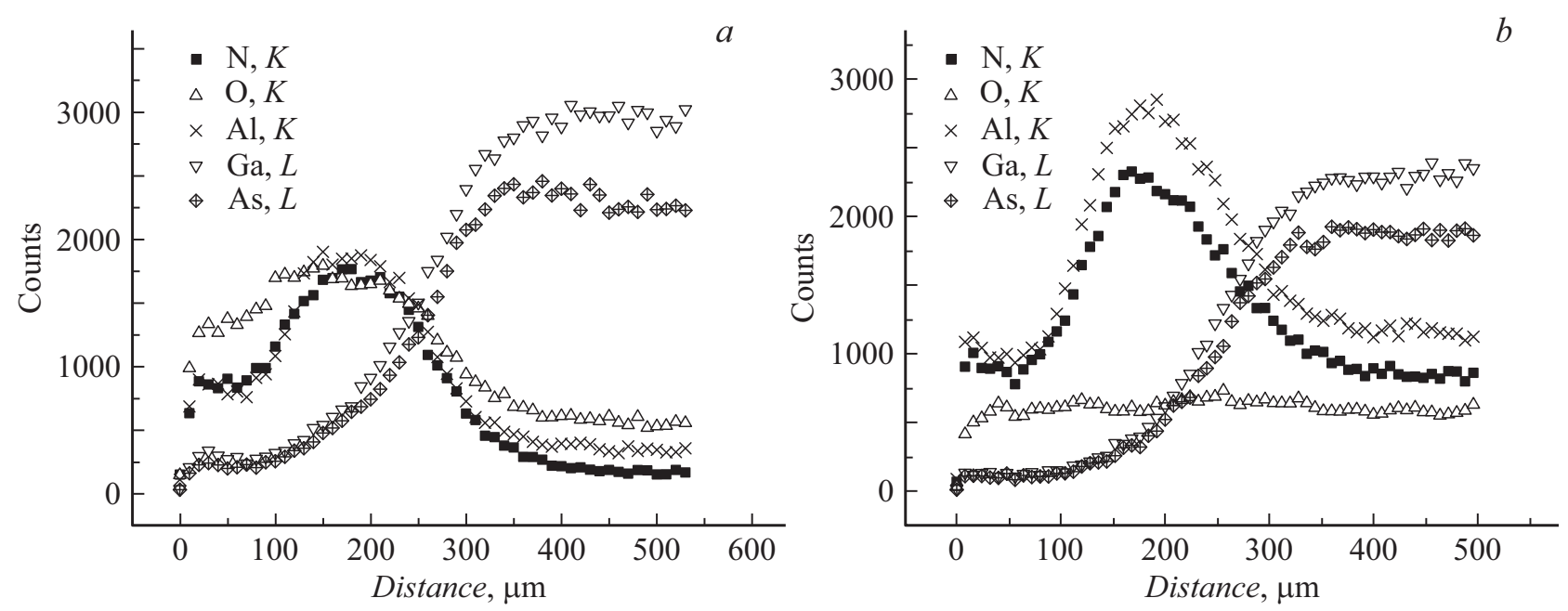

Рис. 2. Распределение элементов в образцах. $a-$ образец № $1, b-$ образец № 2 .

нано- или микрокристаллическую структуру. Показатель преломления имеет значение, близкое к теоретическому, что также подтверждает это предположение. На рис. 2, $a, b$ показаны профили распределения элементов в зависимости от глубины сканирования для образцов № 1 и 2 соответственно. Как видно, при более высоком остаточном давлении в образце № 1 (рис. 2,a) присутствует значительная доля кислорода в области координат, соответствующей пленке $\mathrm{AlN}$. Кроме того, „хвост“ спектра распределения кислорода частично продлевается в область подложки. В образце № 2 (рис. 2,b) интенсивность спектра кислорода является практически константой с низким значением по всей области сканирования, так что можно полагать это шумовым сигналом либо сигналом от кислорода, который успел адсорбироваться на поверхность после образования скола перед измерениями, т.е. кислород в объеме образца № 2, вероятно, отсутствует как в самой пленке, так и в подложке GaAs.

Таким образом, можно заключить, что тонкопленочные покрытия AlN, полученные методом реактивного ионно-плазменного распыления алюминия в среде чистого азота после откачки до остаточного вакуума порядка $\sim 10^{-7}$ Torr, сохраняют барьерные свойства в отношении атмосферного кислорода более полугода. С учетом этого, а также их значительной механической и химической стойкости и огромной температуры термического разложения они могут быть использованы в качестве защитных покрытий для резонаторов мощных полупроводниковых лазеров. Кроме того, в некоторых случаях благодаря своему показателю преломления они одновременно могут выполнять роль просветляющего покрытия. Эти возможности позволяют говорить о существовании перспективной альтернативы предварительной химической пассивации, использованию многослойных покрытий или дорогостоящих технологий раскалывания гетероструктур в вакууме.

\section{Благодарности}

Авторы выражают благодарность кафедре фотоники СПбГЭТУ „ЛЭТИ“, коллективу лаборатории L2N Université de Technologie de Troyes и коллективу лаборатории LRN Université de Reims Champagne-Ardenne за всестороннюю поддержку работы.

\section{Финансирование работы}

Работа в части измерений химического состава пленок выполнена благодаря платформе L2N/LRN NanoMat, поддерживаемой регионом Grand Est, фондами FEDER и DDRT Grand Est. T.M. также выражает благодарность Национальному агентству по исследованиям (проект INSOMNIA, ANR-18-CE09-0003), Высшей школе EIPHI (ANR-17-EURE0002).

\section{Конфликт интересов}

Авторы заявляют, что у них нет конфликта интересов.

\section{Список литературы}

[1] Beister G., Maege J., Erbert G., Tränkle G. // Solid-State Electron. 1998. V. 42. N 11. P. 1939-1945.

[2] Souto J., Pura J.L., Torres A., Jiménez J., Bettiati M., Laruelle F.J. // Microelectron. Reliab. 2016. V. 64. P. 627-630.

[3] Hempel M., Tomm J.W., Ziegler M., Elsaesser T., Michel N., Krakowski M. // Appl. Phys. Lett. 2010. V. 97. N 23. P. 231101. DOI: $10.1063 / 1.3524235$

[4] Bessolov V.N., Lebedev M.V., Shernyakov Y.M., Tsarenkov B.V. // Mater. Sci. Eng. B. 1997. V. 44. P. 380-382.

[5] Ressel P., Erbert G., Zeimer U., Hausler K., Beister G., Sumpf B., Klehr A., Trankle G. // Photon. Technol. Lett. 2005. V. 17. N 5. P. 962-964. 
[6] Shu X., Xu C., Tian Z., Shen G. // Solid-State Electron. 2005. V. 49. N 12. P. 2016-2017.

[7] Chand N., Hobson W.S., de Jong J.F., Parayanthal P., Chakrabarti U.K. // Electron. Lett. 1996. V. 32. N 17. P. $1595-1596$.

[8] Zolotarev V.V., Leshko A.Y., Sokolova Z.N., Lubyanskiy Y.V., Pikhtin N.A., Nikolaev D.N., Shamakhov V.V., Tarasov I.S. // J. Phys.: Conf. Ser. 2016. V. 740. P. 012003.

[9] Анкудинов А.В., Евтихиев В.П., Токранов В.Е., Улин В.П., Титков А.Н. // ФТП. 1999. Т. 33. В. 5. С. 594-597.

[10] Лубянский Я.В., Бондарев А.Д., Сошников И.П., Берт Н.А., Золотарев В.В., Кириленко Д.А., Котляр К.П., Пихтин Н.А., Тарасов И.С. // ФТП. 2018. Т. 52. В. 2. C. $196-200$.

[11] Фомин E.В., Бондарев А.Д., Rumyantseva A.I., Maurer T., Пихтин Н.А., Тарасов С.А. // Письма в ЖТФ. 2019. Т. 45. B. 5. C. $38-41$.

[12] Середин П.В., Федюкин А.В., Терехов В.А., Барков К.А., Арсентьев И.Н., Бондарев А.Д., Фомин Е.В., Пихтин Н.А. // ФТП. 2019. Т. 53. В. 11. С. 1584-1592. 